\title{
Digitalization of transport sphere: relevance and main directions
}

\author{
Polina V. Kharitonova ${ }^{1, *}$, Natalia $V$. Grokhotova ${ }^{1}$, and Evgeniya $V$. Bogdanova ${ }^{2}$ \\ ${ }^{1}$ Bratsk State University, 40, Makarenko str., Bratsk, Russia \\ ${ }^{2}$ Baikal State University (Bratsk branch), 14, Karl-Marx str., Bratsk, Russia
}

\begin{abstract}
The object of this study is the program of digitalization of the transport sector for the purpose of stable and effective development of the Russian economy. The subject of the research is the development of directions for the implementation of the digital economy in road transport. The working hypothesis of the study involves the construction of a systematic understanding of the role of digitalization in the transport sector in the context of improving the country's economy through modern IT technologies. In the existing theory and practice, the idea of the role of digitalization in the transport sector for improving socioeconomic conditions needs to be clarified and supplemented. The theoretical basis of the research was the work of both domestic and foreign scientists devoted to the role of digitalization, including in the transport sector. The information base was the data of the Federal State Statistics Service, legal acts of Russia, information obtained at all-Russian and international conferences devoted to the problems of introducing the digital economy in various spheres of life. The article presents its own vision of the concept of "digital economy", substantiates the relevance and significance of the process of digitalization of the transport sector. The main directions of introducing the digital economy into the provision of services for the transportation of goods and passengers by road are proposed, the implementation of which will ensure stable and effective development of not only the transport industry, but also the country's economy as a whole.
\end{abstract}

Keywords: economy, road transport, digital economy, digitalization, industry economics

\section{Introduction}

Back in 2016 Russian President V.V. Putin set the vector for the development of the national economy, predetermining cardinal changes for the near future, setting the issues of its digitalization as one of the main guidelines. In modern conditions, information is becoming the highest form of knowledge, and the issue of digitalization is acquiring both theoretical and practical significance

In his 2018 Government Address, the President of the Russian Federation proposed a strategy for the development of regions and settlements, which will help improve the quality of life of people. The President noted that modern communications should cover the proposed process through and through.

It is obvious that it is not possible to implement the chosen strategy without modern digital communications. In this light, in our opinion, one of the main tasks requiring a priority solution is the improvement of activities, increasing the efficiency and coherence of the work of transport enterprises through the active introduction of the digital economy.

About the digital economy. Let's consider the terminological component. The concept of "digital economy" appeared relatively recently - in 1995. American economist $\mathrm{N}$. Negroponte was one of the first to raise the question of the need to move the economy to a new level through information and communication technologies [7]. The term "digitalization" itself is widely used in modern conditions, but not everyone fully understands its essential component. After all, digitalization does not mean a global transition to advanced technologies and the ability to be successful and competitive in the market. This is a more complex concept based on a basic change in approaches to solving social and economic problems.

Today the so-called "digital economy" is becoming popular. At the universities of Russia, this direction of training is gaining relevance [9]. In simple terms, the essence of the digital economy is to optimize the turnaround time. Interest in the digital economy is growing every day, and this is evidenced by the number of reports presented at international conferences on world development $[1,2,6]$. Most countries consider digitalization as a priority area for the development of the national economy. It is digitalization that many researchers began to call "digital dividends", which will allow one in the long term to ensure the stable functioning of all sectors of the economy, improve the well-being of citizens, their level of education and development, the quality and transparency of public services provided, and develop other aspects of social and social life [5].

* Corresponding author: hpv83@mail.ru 


\section{Problem Statement}

Due to the large length of the territory of Russia, the significant remoteness of its subjects, the transport industry plays one of the defining roles in the national economy, which confirms the importance and relevance of the task of digitalizing the management of the transport sector.

Currently, Russia is far from being the leader in the development of the digital economy. This is explained by many factors, such as low GDP growth rates and its volumes, lag in the development of IT technologies, etc. Nevertheless, in recent years, some large companies have made significant progress in the field of digital technologies. An example is the Russian multinational company in the information technology industry Yandex.

3 Research Questions

The study raised the following questions:

1. What are the approaches to the definition of the concept of "digital economy"?

2. How is the digitalization process going in the transport sector?

3. What areas of implementation of the digital economy in road transport can be considered the most promising?

\section{Purpose of the Study}

The purpose of the study is the development and addition of theoretical and methodological approaches to the digitalization of the transport sector based on IT technologies in relation to economic processes.

\section{Research Methods}

The present study is based on the systematic approach, for the implementation of which a logical approach, analysis, abstraction, classification and comparison techniques were applied.

\section{Findings}

The emergence of the digital economy in the 90s led to a large number of scientific publications on this topic. Discussions were unfolding in relation to the interpretation of the concept itself. At a seminar on December 20, 2016, the World Bank gave the following definition of the digital economy: "... the paradigm of accelerating economic development ...". A number of researchers understand the digital economy as a virtual environment that complements reality [5].

We cannot fully agree with this definition, since all actions performed in the economic environment are associated with production, distribution, exchange and consumption, and the appearance of these actions is not associated with the creation of computers. It seems to us that the digital economy can be viewed from two points of view. Firstly, as a mechanism of digital technologies (remote control in transport, distance learning, distance medicine, teleshopping, etc.). Secondly, like all economic production using IT technologies.

Currently, there are quite a few ways to develop the digital economy, and all of them are aimed at deep integration of IT technologies in relation to economic processes. Digitalization is focused on the consumer, segment, quality. The market can be changed to the maximum due to: information, which becomes the main resource; the Internet with its unlimited sites for the development of economic relations; competition; development of small and medium-sized businesses.

A number of researchers believe that the digital economy is an economy that is reflected in numbers [3]. In our opinion, this way of reflecting information is a requirement of the time, when in order to solve economic problems it is necessary to quickly find the relevant information and analyze it. In digital form, these actions can be performed as conveniently and quickly as possible. In addition, our modern life today is inextricably linked with the Internet. If you think about it, then in our hands we often take a phone not to make a call, but to access various sites and applications on the Internet. Citizens are increasingly using Internet sites, as it is very convenient, and sometimes much more profitable.

However, it should be noted that the digitalization process is not proceeding at the same pace in all industries. For example, in industries such as mechanical engineering or agriculture, we are not seeing such a rapid transition to digitalization as in the trade sector. This is due, first of all, to the peculiarities of the functioning of industries, their scale, the difficulties of introducing advanced technologies, the availability of sufficient financial resources, the feasibility and return on investment in the development of IT technologies.

Digital economy in the transport sector. Moving significant volumes of various goods, servicing the circulation process, carrying out passenger transportation, transport meets the needs of all other industries, plays the role of a "circulatory system" and therefore is one of the most important sectors of the economy of any state. For Russia, with its long length, given the current state of transport routes, the issues of the advanced development of the transport industry are significantly increasing. Our country is characterized by the presence of vast air, land and sea territories where it is possible to successfully develop unmanned vehicles, logistics using robotics, and use IT technologies. This is exactly what the President of Russia spoke about in his 2018 Address to the Government of the Russian Federation, outlining the vector of development towards the digitalization of the transport sector.

Transport as a sector of the national economy is a structural link of the entire economy as a whole. Therefore, the digitalization of the transport sector is directly related to the development of the digital economy at the national level [8]. The most obvious example of the transition to digital format in the transport sector is the synthesis of digital data between suppliers and buyers of transport services. These are currently the most popular electronic tickets and references. 
The Program proposed by the President of the Russian Federation covers a wide range of issues related to measures for the transition to digitalization, with the platforms used for these purposes, with performance indicators and other significant aspects.

The transition to digitalization in the transport sector should unite all interested participants in this process: involve the spheres of science, education, entrepreneurship and the state. Only close interaction of these participants will allow us to create and build an effective and modern platform for digital transport management. The scientific community is already proposing effective mechanisms for the implementation of digitalization programs in the transport sector. The education sector must prepare competent specialists. The business sector is able to timely identify, indicate emerging problems and difficulties, which will ensure their prompt resolution or elimination. At the state level, it is necessary to develop appropriate regulatory and legal acts to ensure information security. The first steps in this direction have already been taken. So since 28.01.2021 the Federal Law of 31.07.2020, No. 258-FZ "On Experimental Legal Regimes in the Sphere of Digital Innovations in the Russian Federation", comes into force. The introduction of this regime involves the application of special regulation to its participants for a certain period of time, which cannot exceed three years. Decree of the Government of the Russian Federation No. 1750 dated 28.102020 approved the list of technologies used in these regimes.

Thus, the implementation of a systematic approach will make it possible to create on the basis of our country a powerful and unified system of digitalization of the transport environment, which ultimately will help to improve the quality of life of the population and create conditions not only for the efficiency of economic activities of transport companies, but also for the effective functioning of the national economy in the whole. In our opinion, one of the main results of the introduction of the digital economy into the transport sector can be the achievement of equilibrium in the transport services market, when the supply in volume and quality level fully corresponds to demand.

Transport, as a set of all types of communication routes, vehicles, technical and other devices that ensure the process of moving people and goods for various purposes, is classified into different types by the medium of movement, by purpose, by the energy used and other criteria. The most common is land transport, including road transport. The 21 st century is characterized by the active development and improvement of motor vehicles, high travel speeds, and the development of new types of transport. These trends are confirmed by the analysis of the dynamics of registered vehicles in the Russian Federation for the period from 2007 to 2019, which are objects of transport tax in accordance with the Tax Code of the Russian Federation. During the analyzed period, there is an increase in all vehicles by more than one and a half times, the number of ground vehicles increased by $56.88 \%$ and as of 01.01 .2020 amounted to 57,650 thousand units. The share of land vehicles in the total number is quite high and ranges from 97.22 to $98.83 \%$.
The share of road transport accounts for about $80 \%$ of the total number of registered land vehicles, which confirms the relevance of digitalization issues in this area.

Table 1. Dynamics of vehicles registered to entities and individuals according to established order (according to the Federal Tax Service)

\begin{tabular}{|l|c|c|c|c|c|}
\hline \multicolumn{1}{|c|}{ Indicators } & $\mathbf{2 0 0 7}$ & $\mathbf{2 0 1 0}$ & $\mathbf{2 0 1 3}$ & $\mathbf{2 0 1 6}$ & $\mathbf{2 0 1 9}$ \\
\hline $\begin{array}{l}\text { Total vehicles, } \\
\text { thousand units }\end{array}$ & 37796 & 43395 & 52390 & 54744 & 58331 \\
\hline $\begin{array}{l}\text { Growth rate in } \\
\text { relation to 2007 }\end{array}$ & - & 1.1481 & 1.3861 & 1.4484 & 1.5433 \\
\hline $\begin{array}{l}\text { Land vehicles, } \\
\text { thousand units }\end{array}$ & 36747 & 42868 & 51714 & 54051 & 57650 \\
\hline $\begin{array}{l}\text { Growth rate in } \\
\text { relation to 2007 }\end{array}$ & - & 1.1666 & 1.4073 & 1.4709 & 1.5688 \\
\hline $\begin{array}{l}\text { Share of land } \\
\text { vehicles, percent }\end{array}$ & 97.22 & 98.79 & 98.71 & 98.73 & 98.83 \\
\hline
\end{tabular}

Compiled by the authors according to the Reports in form No. 5-TN (consolidated for the Russian Federation) for 2007, 2010, 2013, 2016, 2019. Retrieved from: http://www.nalog.ru

Digitalization in road transport. Today, assessing the development of digitalization in road transport, we can already talk about positive trends and results. This is, first of all, the widespread use of electronic travel documents, ordering transport services via the Internet, the possibility of their non-cash payment and other advantages. For example, a functioning GLONASS system provides users with ample opportunities: for business, it allows you to track the movement of industrial vehicles, monitor the implementation of tasks set by the employer; for citizens it makes it possible to plan a route of movement without waiting for transport at stops for a long time. Modern platforms allow tracking the movement of a vehicle through a smartphone, and all these advantages create more comfortable conditions for consumers of transport services.

Proceeding from the fact that any vehicle is an object of danger, in modern conditions of high speeds, car accidents are one of the factors of increased mortality among children and people of working age. According to the statistics of the Russian Federation, the largest proportion of all car accidents is accidents involving light vehicles. In 2019, this share was $83 \%$. Road accidents involving freight transport account for $8 \%$ of the total number of accidents committed. Note that in recent years, there has been a positive trend in reducing the number of road traffic accidents (Fig. 1). But nevertheless, the issue of safety on Russian roads is still relevant.

An important role in ensuring road safety in modern conditions is assigned to the installation of photo and video recording objects on the roads. Work in this direction is being actively promoted not only in the European part of Russia, but throughout its entire territory and in regions remote from the federal centre.

Created in order to collect payments for compensation for damage caused by heavy vehicles to public roads, the Platon system, in addition to purely fiscal ones, can provide a solution to a number of other 
problems. For example, by registering and tracking freight traffic, it is possible to assess the congestion of roads, and the introduction of registration of the severity of goods transported and their hazard would help inform road users online in order to prevent and ensure their safety.

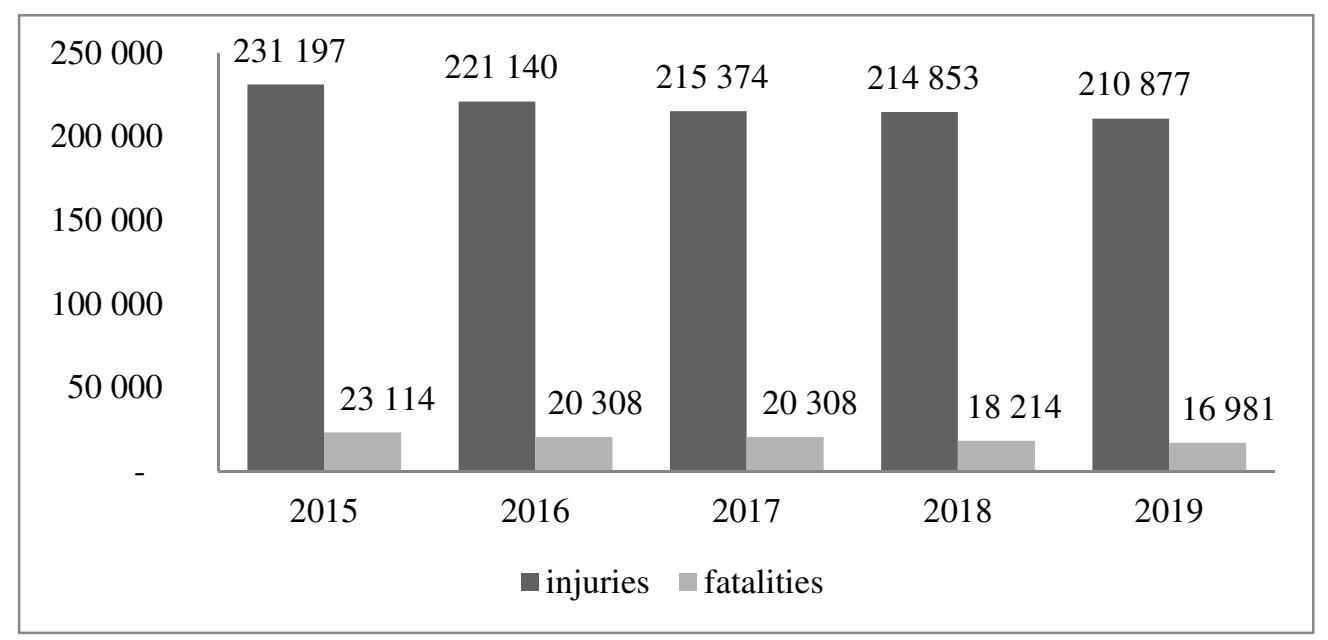

Figure 1. Dynamics of injuries and fatalities in road accidents, people

Nevertheless, at present in Russia the issue of quality and safety of the roadway is still relevant. This problem can also be solved with the use of digitalization. This is stated in the Order of the Government of the Russian Federation dated April 28, 2018 No. 831-r "On approval of the development strategy of the automotive industry of the Russian Federation for the period up to 2025". This document invites, using digital platforms, all road users to send wishes, photos and videos of roads that do not meet the quality and safety requirements. There are similar Internet resources in the regions of the country and are already actively used by caring Russian citizens.

It is gratifying that the partners GLONASS and Platon are currently working on the development of a single digital platform specifically for road transport. Using public-private partnerships, this platform will create additional digital services that help reduce operating costs for both motorists and carriers. It should be noted that this platform will be one of the solutions of the Safe and High-Quality Roads Program, contributing to the development of Russia's transport strategy until 2030.

An intelligent transport system is planned to become a real innovation in the near future. The American company Tesla has already introduced self-driving cars to the market. According to forecasts, ground-based drones will soon become the most anticipated innovative find in the field of digitalization in road transport.

\section{Conclusion}

Digital economy is a completely new look at economic relations around the world; it is a deep integration of IT technologies in relation to economic processes.

It is quite difficult to keep up with the new ideas of the leading countries in the development of the digital economy. Many opportunities are open for Russia to digitize processes in all spheres of activity, especially in transport. It is necessary at the state level to resolve issues of legal regulation in the field of digital innovations, to stimulate investments in the development of IT technologies and their active subsequent implementation in all sectors of the national economy, and especially in the transport sector.

In our opinion the main directions for the implementation of the digital economy in road transport are:

- firstly, ensuring comfortable conditions and efficiency in the provision of transport services to consumers;

- secondly, creating opportunities for regular monitoring and control of the compliance of the roadway with the established requirements for safe operation;

- thirdly, the solution of the problem of ensuring safety by means of remote control of observance of traffic rules by all its participants, with mandatory immediate punishment of the identified violators.

Investments in infrastructure complexes, competition between technological products and education of citizens are the main levers that will accelerate the process of digitalization of the country's economy.

The ideas for the development of digitalization in the transport sector presented in the article, in our opinion, will contribute to the creation of civilized relationships between the spheres of science, education, entrepreneurship and the state, which will ensure the implementation of the transport strategy of the Russian Federation for the period up to 2030 .

\section{References}

1. L.V. Bolshedvorova, V.V. Kosyakova. Information culture as a factor in the development of the information society. In: Current issues of the region's economy: analysis, diagnosis and forecasting (pp. 270-273) (Stimul-ST, Nizhny Novgorod, 2016) 
2. E.G. Grudistova, D.A. Pastuhova, A.M. Slinkov, O.K. Slinkova, T.N. Melnikov. Study of selfactualization needs of Russian students as a factor of competitiveness in the labor market. Espacios, 40(26), 1-11 (2019)

3. L. Kaverzina. Restructuring of the regional investment and construction complex. MATEC Web of Conf. Investment, Construction, Real Estate: New Technologies and Special-Purpose Development Priorities, 212 (2018)

4. L. Kaverzina, G. Kovalenko, I. Dudina, O. Belskii. Cost efficiency assessment of automated quality control of precast structures. MATEC Web of Conf. Youth, Science, Solutions: Ideas and Prospects, 143 (2018)

5. L. Kaverzina, P. Koshevoi, V. Dorofeeva. The improvement of company planning at the building enterprise. IOP Conf. Ser. Mat. Sci. and Eng., 667 (2019)

6. I.I. Lomov, M.Y. Vakhrusheva. Automation of the process of selling and accounting of insurance products in commercial banks. Probl. of socio-econ. develop. of Siberia, 2(32), 64-70 (2018)

7. N. Negroponte. Being digital. (Hodder\&Stoughtong, London, 1995)

8. A.M. Patrusova. Modern information technology assesses the effectiveness of investment IT projects. Modern technol. System anal. Model., 2(42), 92-96 (2014)

9. A.M. Patrusova, M.Y. Vahrusheva. Process management: Some implementation aspects. IOP Conf. Ser. Mat. Sci. and Eng., 753(8) (2020) 